\title{
Investigations on Eco Friendly Insulating Fluids from Rapeseed and Pongamia Pinnata Oils for Power Transformer Applications
}

\author{
R. Thanigaiselvan ${ }^{\dagger}$, T. Sree Renga Raja* and R.Karthik**
}

\begin{abstract}
Transformer mineral oil which is normally hydrocarbon based is non- biodegradable and pollutes the environment in all aspects. Though vegetable oils are eco-friendly in nature and potentially could be used in transformers as a replacement for the mineral oil, there usage is restricted because of their oxidative instability. The present work focuses on using rapeseed oil and pongamia (pongamia pinnata) oil as effective alternatives for the traditional mineral oil in power transformer. The oxidative stability of the rapeseed oil and pongamia oil is increased by using combinations of the natural and synthetic anti-oxidants as additives. The parameters like breakdown voltage, viscosity, flash point, fire point are measured for the rapeseed oil and pongamia oil with and without the additives as per IEC and ASTM standards. The results shown encouraging changes in the parameter values and ensures the use of the oils as a potential alternative insulation in power transformers.
\end{abstract}

Keywords: Anti-oxidants, Eco-friendly oil, Oxidative stability, Power transformers.

\section{Introduction}

The Polychloro biphenyl (PCB) was used as a nonflammable insulating fluid in transformers since 1932[1] and until 1979. PCB a highly toxic material and is classified as persistent organic pollutant. Hence PCB productions were banned by the United States Congress in 1979 and by the Stockholm Convention on Persistent Organic Pollutants in 2001[2]. Later in 1978 as an alternative for the PCB, Isopropyl biphenyl was used as the dielectric insulating fluid in the power transformers [3]. In addition, silicone fluids like polydimethyl siloxane (PDMS) and high temperature hydro carbons (HTH) were also used $[4,5]$. Though their insulating property was found to be excellent both of them are flammable liquids with high fire point. Synthetic liquids like Ester, Perchloro ethylene are also used, as they have good dielectric strength and heat transfer characteristics, their high cost notwithstanding. Crude oil based mineral oil are refined in such a way as to get the desirable property of insulation. The transformer mineral oil is non-biodegradable, besides heavily polluting land and water. Several billion litres of transformer oils are being used worldwide in the power transformers as insulating and cooling medium [6]. Nowadays, the faster exploitation of petroleum products makes it necessary to conserve and reduce its usage. Considering the environmental pollution it creates the need for alternative sources for replacement of the transformer

$\dagger$ Corresponding Author: Dept. of EEE, Anna University, Bharathidasan Institute of Technology, India. (rthanigaiselvan@gmail.com)

* Dept. of EEE, Anna University, Bharathidasan Institute of Technology, India. (renga_raja@rediffmail.com)

** Liquid Dielectrics Laboratory, Dept. of EEE., National Engineering College, India. (hvekarthik@gmail.com)

Received: September 20, 2014; Accepted: June 19, 2015 mineral oils. Vegetable oils are the alternative sources which come in handy and are available in plenty. The usage of vegetable oils for power capacitors was suggested in 1990s $[7,8]$. The vegetable oils like coconut oil, sunflower oil were used in transformers $[9,10]$. The vegetable oils are being used in transformers and they satisfy the industry standards with regard to performance and other aspects [11].

Though we have advantages in using the vegetable oils, there are some disadvantages too like high viscosity and poor oxidative stability [12]. As the vegetable oils are lacking in oxidative stability, they are used less in the industries. The natural ester's [Vegetable oil] oxidation stability and performance depends on the composition of the fatty acids. The decrease in the oxidative stability and the shelf life of the oil is due to the removal of antioxidants [13].The antioxidants are the chemical compounds which forbid the oxidation process due to oxygen. Its function is to interrupt the propagation of the free radical chain. The popular antioxidants are hydroxyl phenol compounds. Some of the phenolic antioxidants include Butylated Hydroxyanisole (BHA), Butylated Hydroxytoluene (BHT), Propyl Gallate (PG) and the natural antioxidants ascorbic acids, $\alpha$ - tocopherole and these were selected after careful study. Raymon et al., performed various analyses in natural oils like sunflower, soya bean, rice bran, corn oil [14] and in this work the rapeseed oil and pongamia oil in combination with and without additives were selected and studied their insulating properties.

\section{Additives}

The antioxidants and synergists are used as the additives 
and catalysts respectively for improvement of the oxidation stability.

\subsection{Antioxidant}

An antioxidant is a chemical substance that forbids the attack of oxygen which is the oxidation process [15]. The antioxidants interrupt the oxidation process by reacting with fat radical to form a stable radical; this does not react with oxygen. In food industry it is called food additive which increases the shelf life of foods by protecting them against deterioration due to oxidation. Antioxidants decrease the action of formation of free alkyl radicals and thereby interrupting the dispersion of free radical chain. It also acts as hydrogen donor which helps in reducing the dispersion of free radical chain. The general form of the reaction is shown as

$$
\begin{gathered}
R \cdot+A H \rightarrow R H+A \cdot \\
R O \cdot+A H \rightarrow R O H+A \cdot \\
R O O \cdot+A H \rightarrow R O O H+A \cdot \\
R \cdot+A \cdot \rightarrow R A \\
R O \cdot+A \cdot \rightarrow R O A \\
R O O+A \cdot \rightarrow R O O A \\
\text { Antioxidant }+O_{2} \rightarrow \text { Oxidized Antioxidant }
\end{gathered}
$$

$$
\begin{aligned}
& R \cdot \text { - Alkyl radical of fatty acid } \\
& A H-\text { Antioxidant } \\
& R H, R O H, R O O H \text { - Fatty acid } \\
& A \cdot-A \text { ntioxidant radical } \\
& R O \cdot \text { - Alkoxy radical } \\
& R O O \cdot \text { - Peroxy radical }
\end{aligned}
$$

The alkyl radical (R·), alkoxy radical (RO·), peroxy radical (ROO) of fatty acid reacts with the antioxidant $(\mathrm{AH})$ and gives the fatty acid $\mathrm{RH}, \mathrm{ROH}, \mathrm{ROOH}$ and antioxidant radical (A.)(Eq. 1,2,3). The alkyl radical, alkoxy radical and peroxy radical with antioxidant radical reacts and gives a non-radical product such as RA, ROA and ROOA (Eq. 4, 5, 6). In the process of neutralizing the free radicals, the antioxidants become oxidized, thereby increasing the process of oxidation (Eq. 7). Hence, there is a constant need of filling of antioxidant sources [16].

The most popular antioxidants are hydroxylphenol compounds. They have low activation energies for hydrogen donation process. The antioxidant free radicals do not

\begin{tabular}{|c|c|c|c|}
\hline \multicolumn{2}{|c|}{ Natural Antioxidant } & $\begin{array}{c}\text { Synthetic } \\
\text { Antioxidant }\end{array}$ & Synergists \\
\hline $\begin{array}{l}\text { Vitamin-E } \\
\text { (TOCO } \\
\text { PHEROL) }\end{array}$ & $\begin{array}{c}\text { Vitamin-E } \\
\text { (TOCO } \\
\text { TRIENOL) } \\
\end{array}$ & \multirow{2}{*}{$\begin{array}{c}\text { Butylated } \\
\text { Hydroxy Anisole } \\
\\
\text { Butylated } \\
\text { Hydroxy Toluene }\end{array}$} & \multirow[b]{2}{*}{ Carsonic Acid } \\
\hline \multicolumn{2}{|c|}{$\operatorname{Alpha}(\alpha)$} & & \\
\hline \multicolumn{2}{|c|}{$\operatorname{Beta}(\beta)$} & Propyl Gallate & Phosphoric Acid \\
\hline \multicolumn{2}{|c|}{$\operatorname{Gamma}(\gamma)$} & Pyrogallol & $\begin{array}{l}\text { Ethylene Diamene } \\
\text { tetra-acetic acid }\end{array}$ \\
\hline \multirow{2}{*}{\multicolumn{2}{|c|}{$\operatorname{Delta}(\delta)$}} & $\begin{array}{c}\text { Lauryl Tert Butyl } \\
\text { Hydro Quinone }\end{array}$ & \\
\hline & & $\begin{array}{c}2,4,5 \text { - Trihydroxy } \\
\text { butyrophenone }\end{array}$ & $\begin{array}{c}\text { Oryzanol } \\
\text { Rosemary Extracts }\end{array}$ \\
\hline
\end{tabular}
initiate other free radicals immediately. They react with the lipid free radicals to form stable compounds. It functions as oxygen interceptors in the oxidative process thereby breaking the chain reaction which slows down the oxidation process. Some common phenolic antioxidants are Butylated Hydroxy Anisole (BHA), Butylated Hydroxy Toluene (BHT), Propyl Gallate (PG) and Tertiary Butyl Hydro Quinone (TBHQ). Obviously, they donate hydrogen to the free radicals and form as a complex between a lipid radical and the antioxidant radical because of the loss of the hydrogen. The types of antioxidants are listed in Table 1.
Table 1. Types of Antioxidants

\subsection{Synergists}

The important substance used for increase of the oxidation stability is the synergist. Synergists are the chemical substances which used to increase the effectiveness of a primary antioxidant. The copper and iron metallic ions act as pro oxidants which are the catalyst in oxidation process. Synergists are more effective when used along with an antioxidant rather than in isolation. Some of the synergists are citric acid, phosphoric acid, and some of their derivatives. The study shows that citric acid can be used in conjunction with the phenolic acid as a synergist $[17,18]$.

\subsection{Eco-friendly fluids}

The rapeseed oil $[19,20]$ and pongamia oil $[21,22]$ were used as base fluid for testing. These oils are rich in oleic acid and were selected due to inherent higher stability of high oleic oils over commercial oils [23]. The Table 2 shows the fatty acid composition of oils [24]. The oils were subjected to vacuum chamber and pressure of $50 \mathrm{~Pa}$ was maintained upto 48 hours for degasifying to remove the moisture content from it. The various parameters like flash point, fire point, viscosity, breakdown voltage of the base fluids were tested and the results are shown in the Table 2.The base fluid 1 and 2 were mixed with various combinations in the proportions of $2.5 \mathrm{~g}$ and $5 \mathrm{~g}$ of antioxidants to measure the performance of it. In addition,

Table 2. Composition of fatty acids in oils

\begin{tabular}{c|ccc|ccc}
\hline \multirow{4}{*}{$\begin{array}{c}\text { Rapeseed } \\
\text { oil }\end{array}$} & \multicolumn{3}{|c|}{ Saturated fatty acid } & \multicolumn{3}{c}{ Unsaturated fatty acid } \\
\cline { 2 - 7 } & $\mathrm{Wt} \%$ & Name & Symbol & $\mathrm{Wt} \%$ & Name & Symbol \\
\cline { 2 - 7 } & 4 & Palmitic & $16: 0$ & 56 & Oleic & $18: 1$ \\
\cline { 2 - 7 } & 2 & Stearic & $18: 0$ & 26 & Linoleic & $18: 2$ \\
\cline { 2 - 7 } & 11.65 & Palmitic & $16: 0$ & 51.59 & Oleic & $18: 1$ \\
\hline $\begin{array}{c}\text { Pongamia } \\
\text { pinnata oil }\end{array}$ & 7.50 & Stearic & $18: 0$ & 16.64 & Linoleic & $18: 2$ \\
\hline
\end{tabular}


Table 3. Test results of base fluids

\begin{tabular}{c|c|c}
\hline Critical Parameters & $\begin{array}{c}\text { Base Fluid 1 } \\
\text { (Rapeseed) }\end{array}$ & $\begin{array}{c}\text { Base Fluid 2 } \\
\text { (Pongamia pinnata) }\end{array}$ \\
\hline Breakdown voltage $(\mathrm{KV})$ & 32 & 27 \\
\hline Viscosity $\left(\right.$ Cst) at $40^{\circ} \mathrm{C}$ & 62 & 32 \\
\hline Flash Point $\left({ }^{\circ} \mathrm{C}\right)$ & 320 & 240 \\
\hline Fire Point $\left({ }^{\circ} \mathrm{C}\right)$ & 340 & 255 \\
\hline
\end{tabular}

multiple combinations of antioxidants were also used in the ratio of 1:1 with the base oil. The breakdown voltages were measured as per the standard IEC 60156 at ambient temperature. The results of the samples with and without additives were compared and discussed.

\section{Sample Preparation}

The base oil of required quantity was taken and moisture content was measured using the Karl Fisher iteration method according to ASTM D6304. The moisture content was removed by drying the oil with silica gel pellets in the ratio of $1 \mathrm{~g}$ of silica to $100 \mathrm{ml}$ of oil with a constant stirring of $500 \mathrm{rpm}$ for 6 hours. The moisture content of oil was less than 10ppm after drying. The antioxidants used as additives were of the purity grades above $99 \%$ and for investigation purpose the weight of $2.5 \mathrm{~g}$ and $5 \mathrm{~g}$ with ratio of 1:1 was chosen. Each antioxidant of $2.5 \mathrm{~g}$ and $5 \mathrm{~g} \mathrm{(1:1)}$ was directly dissolved in $500 \mathrm{ml}$ of base oils. As there is no particular standard of temperature for mixing antioxidant with oil, we have maintained the room temperature with an increase up to $40^{\circ} \mathrm{C}$. The combinations of them were heated to a temperature of $40^{\circ} \mathrm{C}$. Then the mixing of antioxidant and base oil was carried out thoroughly by means of vigorous mechanical agitator like
Table 4. Abbrevation and functions of antioxidants

\begin{tabular}{|c|c|c|c|}
\hline $\begin{array}{l}\text { Chemical name and } \\
\text { formula }\end{array}$ & $\begin{array}{l}\text { Abbreviated } \\
\text { as }\end{array}$ & Origin & Application \\
\hline $\begin{array}{c}\alpha \text {-Tocopherol Acetate } \\
\left(\mathrm{C}_{31} \mathrm{H}_{52} \mathrm{O}_{3}\right)\end{array}$ & $\alpha-\mathrm{T}$ & \multirow{3}{*}{ Natural } & $\begin{array}{c}\text { Quenchers of singlet } \\
\text { oxygen/Synergist }\end{array}$ \\
\hline $\begin{array}{c}\text { Citric Acid } \\
\text { (anhydrous) }\left(\mathrm{C}_{6} \mathrm{H}_{8} \mathrm{O}_{7}\right)\end{array}$ & $\mathrm{CA}$ & & $\begin{array}{c}\text { Singlet oxygen } \\
\text { scavengers/Synergist }\end{array}$ \\
\hline $\begin{array}{l}\text { L-Ascorbic acid } \\
\left(\mathrm{C}_{6} \mathrm{H}_{8} \mathrm{O}_{6}\right)\end{array}$ & AA & & $\begin{array}{c}\text { Oxygen Scavengers } \\
\text { Synergist }\end{array}$ \\
\hline $\begin{array}{l}\text { Butylated Hydroxy } \\
\text { Anisole }\left(\mathrm{C}_{11} \mathrm{H}_{16} \mathrm{O}_{2}\right)\end{array}$ & BHA & \multirow{3}{*}{ Synthetic } & $\begin{array}{l}\text { Free radical } \\
\text { Scavengers }\end{array}$ \\
\hline $\begin{array}{l}\text { Butylated Hydroxy } \\
\text { Toluene }\left(\mathrm{C}_{15} \mathrm{H}_{24} \mathrm{O}\right)\end{array}$ & BHT & & $\begin{array}{c}\text { Free radical } \\
\text { scavengers }\end{array}$ \\
\hline $\begin{array}{c}\text { Propyl Gallate } \\
\left(\mathrm{C}_{10} \mathrm{H}_{12} \mathrm{O}_{5}\right)\end{array}$ & PG & & $\begin{array}{l}\text { Free radical } \\
\text { scavengers }\end{array}$ \\
\hline
\end{tabular}

ultra sonicator. The additives were dissolved completely in base oils. Around forty samples were prepared according to standards and Table 5 shows the samples prepared with two base fluids and their combinations with antioxidants.

\section{Testing of Samples}

The samples were prepared with several combinations of antioxidants and synergists according to the standard procedures. The measurements of breakdown voltage, Flash point, Fire point, and viscosity of the prepared samples were carried out with standard test procedure as follows:

\subsection{Breakdown voltage}

The dielectric breakdown voltage of an insulating liquid is a measure of liquid's ability to withstand electric stress

Table 5. Samples prepared with Base fluids and the antioxidants

\begin{tabular}{|c|c|c|c|}
\hline \multicolumn{2}{|r|}{ Samples from Base fluid 1} & \multicolumn{2}{|r|}{ Samples from Base fluid 2} \\
\hline Samples & Combinations of antioxidants & Samples & Combinations of antioxidants \\
\hline $\mathrm{S} 1$ & Base fluid $1+5 \operatorname{gm} \alpha-\mathrm{T}$ & $\mathrm{S} 21$ & Base fluid $2+5 \operatorname{gm} \alpha-\mathrm{T}$ \\
\hline $\mathrm{S} 2$ & Base fluid $1+2.5 \mathrm{gm} \alpha-\mathrm{T}$ & $\mathrm{S} 22$ & Base fluid $2+2.5 \operatorname{gm} \alpha-\mathrm{T}$ \\
\hline S3 & Base fluid $1+5 \mathrm{gm} \mathrm{AA}$ & $\mathrm{S} 23$ & Base fluid $2+5$ gm AA \\
\hline $\mathrm{S} 4$ & Base fluid $1+2.5$ gm AA & $\mathrm{S} 24$ & Base fluid $2+2.5 \mathrm{gm} \mathrm{AA}$ \\
\hline S5 & Base fluid $1+5$ gm CA & $\mathrm{S} 25$ & Base fluid $2+5$ gm CA \\
\hline S6 & Base fluid $1+2.5$ gm CA & $\mathrm{S} 26$ & Base fluid $2+2.5$ gm CA \\
\hline S7 & Base fluid $1+5$ gm BHA & $\mathrm{S} 27$ & Base fluid $2+5$ gm BHA \\
\hline S8 & Base fluid $1+2.5$ gm BHA & $\mathrm{S} 28$ & Base fluid $2+2.5$ gm BHA \\
\hline S9 & Base fluid $1+5$ gm BHT & S29 & Base fluid $2+5 \mathrm{gm} \mathrm{BHT}$ \\
\hline S10 & Base fluid $1+2.5$ gm BHT & $\mathrm{S} 30$ & Base fluid $2+2.5 \mathrm{gm} \mathrm{BHT}$ \\
\hline S11 & Base fluid $1+5$ gm PG & S31 & Base fluid $2+5$ gm PG \\
\hline $\mathrm{S} 12$ & Base fluid $1+2.5 \mathrm{gm} \mathrm{PG}$ & $\mathrm{S} 32$ & Base fluid $2+2.5 \mathrm{gm} \mathrm{PG}$ \\
\hline $\mathrm{S} 13$ & Base fluid $1+2.5 \mathrm{gm} \mathrm{BHA}+2.5 \mathrm{gm} \mathrm{BHT}$ & $\mathrm{S} 33$ & Base fluid $2+2.5 \mathrm{gm} \mathrm{BHA}+2.5 \mathrm{gm} \mathrm{BHT}$ \\
\hline $\mathrm{S} 14$ & Base fluid $1+1.25 \mathrm{gm} \mathrm{BHA}+1.25 \mathrm{gm} \mathrm{BHT}$ & $\mathrm{S} 34$ & Base fluid $2+1.25 \mathrm{gm} \mathrm{BHA}+1.25 \mathrm{gm} \mathrm{BHT}$ \\
\hline S15 & Base fluid $1+2.5 \mathrm{gm} \mathrm{BHT}+2.5 \mathrm{gm} \mathrm{CA}$ & $\mathrm{S} 35$ & Base fluid $2+2.5 \mathrm{gm} \mathrm{BHT}+2.5 \mathrm{gm} \mathrm{CA}$ \\
\hline S16 & Base fluid $1+1.25 \mathrm{gm} \mathrm{BHT}+1.25 \mathrm{gm} \mathrm{CA}$ & $\mathrm{S} 36$ & Base fluid $2+1.25$ gm BHT+1.25 gm CA \\
\hline $\mathrm{S} 17$ & Base fluid $1+2.5 \mathrm{gm} \mathrm{BHT}+2.5 \mathrm{gm} \mathrm{AA}$ & $\mathrm{S} 37$ & Base fluid $2+2.5 \mathrm{gm} \mathrm{BHT}+2.5 \mathrm{gm} \mathrm{AA}$ \\
\hline $\mathrm{S} 18$ & Base fluid $1+1.25 \mathrm{gm} \mathrm{BHT}+1.25 \mathrm{gm} \mathrm{AA}$ & $\mathrm{S} 38$ & Base fluid $2+1.25 \mathrm{gm} \mathrm{BHT}+1.25 \mathrm{gm} \mathrm{AA}$ \\
\hline S19 & Base fluid $1+2.5 \operatorname{gm~BHT}+2.5 \operatorname{gm} \alpha-\mathrm{T}$ & S39 & Base fluid $2+2.5 \mathrm{gm} \mathrm{BHT}+2.5 \mathrm{gm} \alpha-\mathrm{T}$ \\
\hline $\mathrm{S} 20$ & Base fluid $1+1.25 \mathrm{gm} \mathrm{BHT}+1.25 \mathrm{gm} \alpha-\mathrm{T}$ & $\mathrm{S} 40$ & Base fluid $2+1.25 \mathrm{gm} \mathrm{BHT}+1.25 \mathrm{gm} \alpha-\mathrm{T}$ \\
\hline
\end{tabular}


without failure. The dielectric breakdown voltage indicates the presence of contaminating agents such as water, air bubble, dirt, cellulosic fibers, or conducting particles in the liquid. The breakdown voltage was measured as per the standard IEC 60156 with the kit voltage capacity of $60 \mathrm{KV}$. The test was conducted with spherical head electrodes of standard diameter with a gap of $2.5 \mathrm{~mm}$ between them. The oil sample of $500 \mathrm{ml}$ was filled up to a level of $40 \mathrm{~mm}$ above the electrodes. After filling of sample, a time period of $5-10$ minutes was allowed for settling of air bubbles in the container. Then the test voltage was increased at the rate of $2 \mathrm{kV} / \mathrm{s}$. Five consecutive breakdown voltages were measured with a stand time of 3-5 minutes for each measurement in order to make the byproducts disperse. The average of five voltages was taken as the breakdown voltage of the sample [25]. The sample was tested at room temperature.

\subsection{Flash point and fire point}

The flash point of the sample was measured with Pensky-Martens closed cup tester according to the standard of ASTM D 93. The brass test cup was filled with the sample of $50 \mathrm{ml}$ and fitted with a lid. Sample in the container was heated and stirred at specified rates and a test flame was introduced into the cup at regular intervals with the interruption of stirring until a flash that spreads throughout inside the cup was seen for one second. The corresponding temperature measured is the flash point of sample. The temperature at which flash in the sample sustains for more than five seconds after ignition by open flame is the fire point and it is also measured for the sample. The sample was tested at the room temperature.

\subsection{Viscosity}

The viscosity of sample was measured using the Saybolt Universal viscometer. The oil sample of $60 \mathrm{ml}$ was taken in brass cup with the size of orifice according to the standard ASTM D88. The cup was surrounded by constant temperature bath to maintain the sample at constant temperature. After filling the cup, the cap was removed so that the oil would flow into receiving flask and at the same time the timer was started. The time taken for the flow of $60 \mathrm{ml}$ was measured and the viscosity of the sample calculated. The sample was tested at room pressure. The viscosity helps in the process of heat convection in the transformers. The smaller the value of viscosity, higher the rate of heat transfer in transformers [26, 27].

\section{Results and Discussions}

\subsection{Breakdown voltage}

The breakdown voltage values of samples are tabulated in Table 6 and these are represented in Figs. 1 - 6. The samples S14 and S19 of base fluid 1 show increase in breakdown voltage by $59 \%$ and $63 \%$ respectively. The samples S33, S39 of base fluid 2 show increase in breakdown voltage by $88 \%$ and $59 \%$ respectively. Though it seems that the percentage enhancement in breakdown voltage is more for base fluid 2 , the mean value of breakdown voltage is less than that of the base fluid 1. The combination of Butylated Hydroxy Anisole and Butylated Hydroxy Toluene, Butylated Hydroxy Anisole and $\alpha$ Tocopherol enhances the dielectric strength to a satisfied level. The base fluid treated with antioxidants releases less amount of carbon and this helps in reducing the gas

Table 6. Breakdown voltage of base fluids with antioxidants

\begin{tabular}{|c|c|c|c|}
\hline Antioxidants & $\begin{array}{l}\text { Weight in } \\
\text { grams }\end{array}$ & $\begin{array}{c}\text { Base Fluid } 1 \\
(\mathrm{Kv})\end{array}$ & $\begin{array}{c}\text { Base Fluid } 2 \\
(\mathrm{Kv})\end{array}$ \\
\hline \multirow{2}{*}{$\alpha-$ TOCOPHEROL } & 5 & 42 & 36 \\
\hline & 2.5 & 39 & 35 \\
\hline \multirow{2}{*}{ Ascorbic acid } & 5 & 25 & 26 \\
\hline & 2.5 & 24 & 25 \\
\hline \multirow{2}{*}{ Citric acid } & 5 & 27 & 28 \\
\hline & 2.5 & 27 & 29 \\
\hline \multirow{2}{*}{ BHA } & 5 & 46 & 36 \\
\hline & 2.5 & 44 & 34 \\
\hline \multirow{2}{*}{ BHT } & 5 & 48 & 36 \\
\hline & 2.5 & 45 & 32 \\
\hline \multirow{2}{*}{ PG } & 5 & 32 & 39 \\
\hline & 2.5 & 30 & 35 \\
\hline \multirow{2}{*}{$\mathrm{BHA}+\mathrm{BHT}$} & $2.5+2.5$ & 49 & 51 \\
\hline & $1.25+1.25$ & 51 & 48 \\
\hline \multirow{2}{*}{$\mathrm{BHT}+\mathrm{CA}$} & $2.5+2.5$ & 49 & 35 \\
\hline & $1.25+1.25$ & 44 & 35 \\
\hline \multirow{2}{*}{$\mathrm{BHT}+\mathrm{AA}$} & $2.5+2.5$ & 43 & 37 \\
\hline & $1.25+1.25$ & 41 & 35 \\
\hline \multirow{2}{*}{$\mathrm{BHT}+\alpha-\mathrm{T}$} & $2.5+2.5$ & 52 & 43 \\
\hline & $1.25+1.25$ & 49 & 38 \\
\hline
\end{tabular}

Table 7. Viscosity of the base fluids with antioxidants

\begin{tabular}{|c|c|c|c|}
\hline Antioxidants & $\begin{array}{l}\text { Weight } \\
\text { in grams }\end{array}$ & $\begin{array}{l}\text { Base Fluid } 1 \\
(\mathrm{cSt}) \text { at } 40^{\circ} \mathrm{C}\end{array}$ & $\begin{array}{l}\text { Base Fluid } 2 \\
(\mathrm{cSt}) \text { at } 40^{\circ} \mathrm{C}\end{array}$ \\
\hline \multirow{2}{*}{$\alpha-$ TOCOPHEROL } & 5 & 56 & 28 \\
\hline & 2.5 & 52 & 25 \\
\hline \multirow{2}{*}{ Ascorbic acid } & 5 & 58 & 27 \\
\hline & 2.5 & 56 & 24 \\
\hline \multirow{2}{*}{ Citric acid } & 5 & 55 & 26 \\
\hline & 2.5 & 52 & 25 \\
\hline \multirow{2}{*}{ BHA } & 5 & 57 & 28 \\
\hline & 2.5 & 54 & 27 \\
\hline \multirow{2}{*}{ BHT } & 5 & 58 & 29 \\
\hline & 2.5 & 54 & 26 \\
\hline \multirow{2}{*}{ PG } & 5 & 56 & 26 \\
\hline & 2.5 & 52 & 24 \\
\hline \multirow{2}{*}{$\mathrm{BHA}+\mathrm{BHT}$} & $2.5+2.5$ & 48 & 27 \\
\hline & $1.25+1.25$ & 42 & 25 \\
\hline \multirow{2}{*}{$\mathrm{BHT}+\mathrm{CA}$} & $2.5+2.5$ & 50 & 26 \\
\hline & $1.25+1.25$ & 48 & 25 \\
\hline \multirow{2}{*}{$\mathrm{BHT}+\mathrm{AA}$} & $2.5+1.5$ & 52 & 27 \\
\hline & $1.25+1.25$ & 50 & 25 \\
\hline \multirow{2}{*}{$\mathrm{BHT}+\alpha-\mathrm{T}$} & $2.5+2.5$ & 45 & 27 \\
\hline & $1.25+1.25$ & 42 & 25 \\
\hline
\end{tabular}




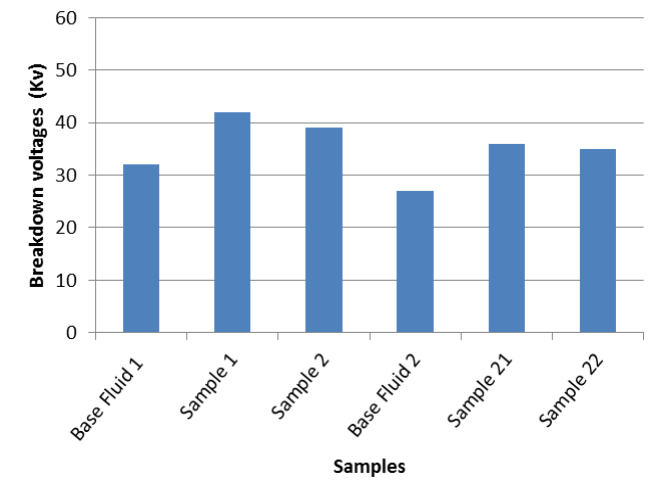

Fig. 1. Breakdown voltage characteristics of base fluid 1 and 2 with $\alpha$ - Tocopherol

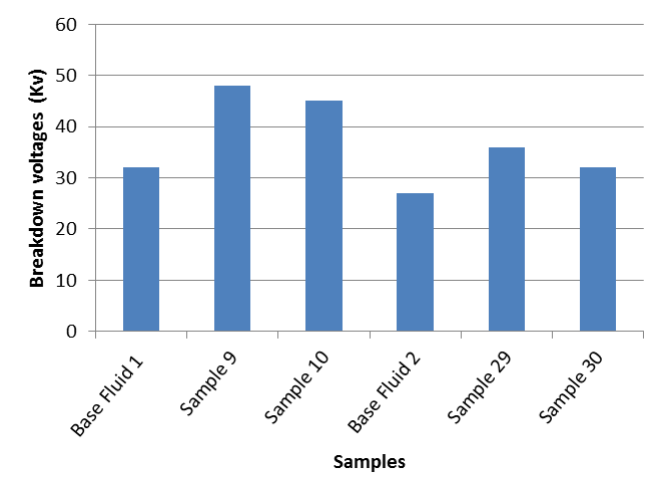

Fig. 2. Breakdown voltage characteristics of base fluid 1 and 2 with Butylated Hydroxy Toluene

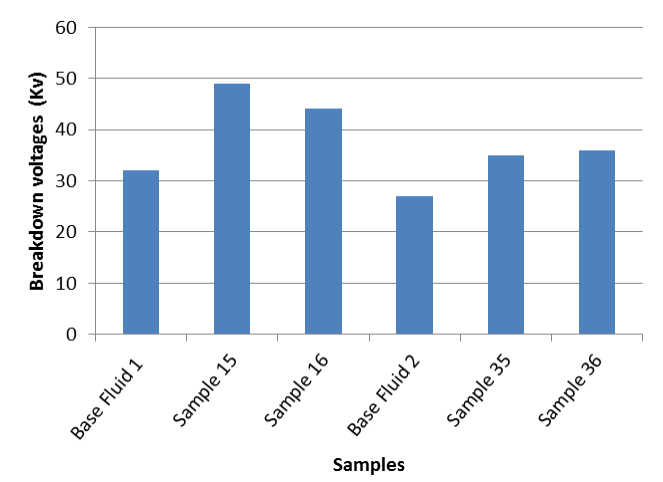

Fig. 3. Breakdown voltage characteristics of base fluid 1 and 2 with Butylated Hydroxy Toluene and Citric acid

formation [28].

\subsection{Flash and fire points}

Antioxidants terminate the formation of chain reaction due to free radicals and reduce the oxidation reactions. The flash and fire point of samples are tabulated in Table 8 and these are represented in the Figs. 7 and 8 . The samples 13, 19, 33, 39 prepared with the combination of the Butylated Hydroxy Toluene and $\alpha$-Tocopherol, Butylated Hydroxy Anisole, and Butylated Hydroxy Toluene with higher concentration have more thermal stability and show a

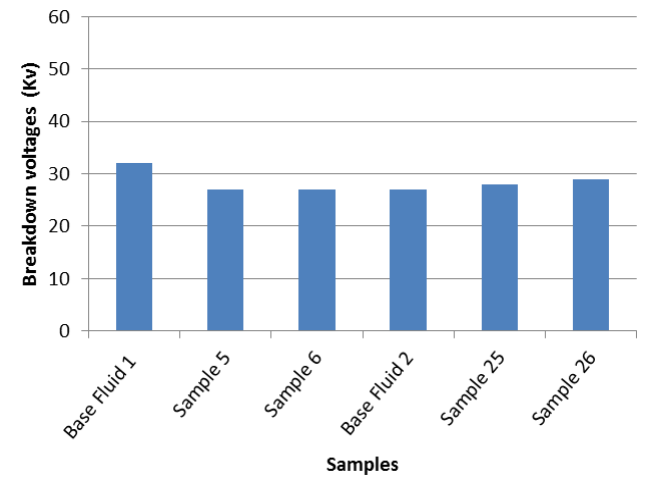

Fig. 4. Breakdown voltage characteristics of base fluid 1 and 2 with Citric acid

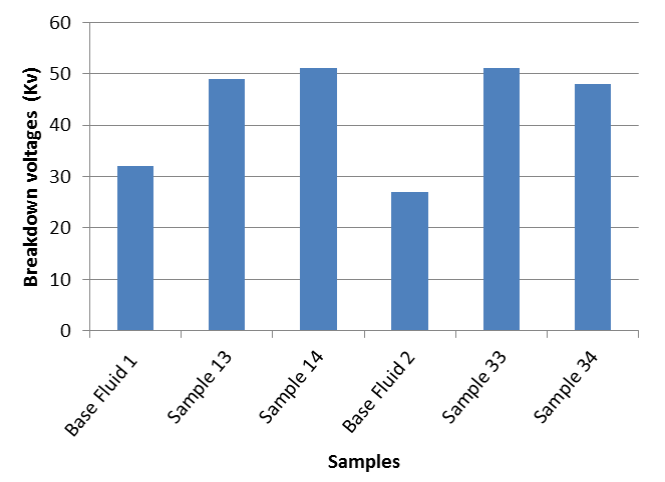

Fig. 5. Breakdown voltage characteristics of base fluid 1 and 2 with Butylated Hydroxy Anisole and Butylated Hydroxy Toluene

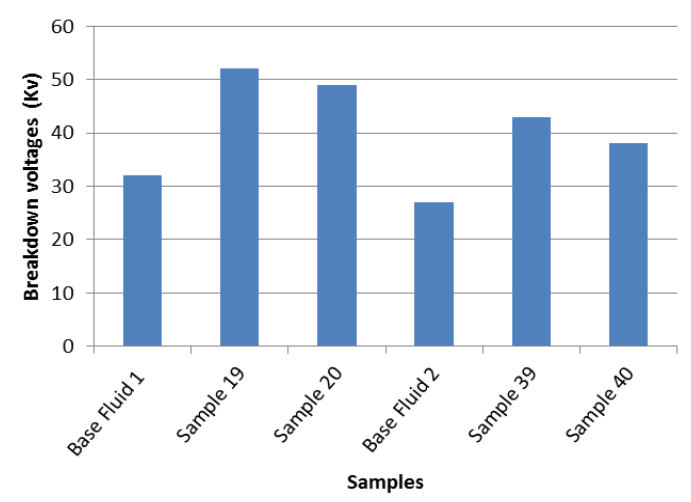

Fig. 6. Breakdown voltage characteristics base fluid 1 and 2 with Butylated Hydroxy Toluene and $\alpha-$ Tocopherol

good enhancement of flash and fire points because of the presence of natural tocopherol and Butylated Hydroxy Anisole. The antioxidant reacts with free radicals and reduces the formation of peroxides thereby reducing oxidation. And also the ability of antioxidant to protect the base fluid depends upon the content of fatty acid of it. The sample prepared with citric acid shows a lesser enhancement of flash and fire points due to the higher rate of ignition mixture formed during the reaction. 


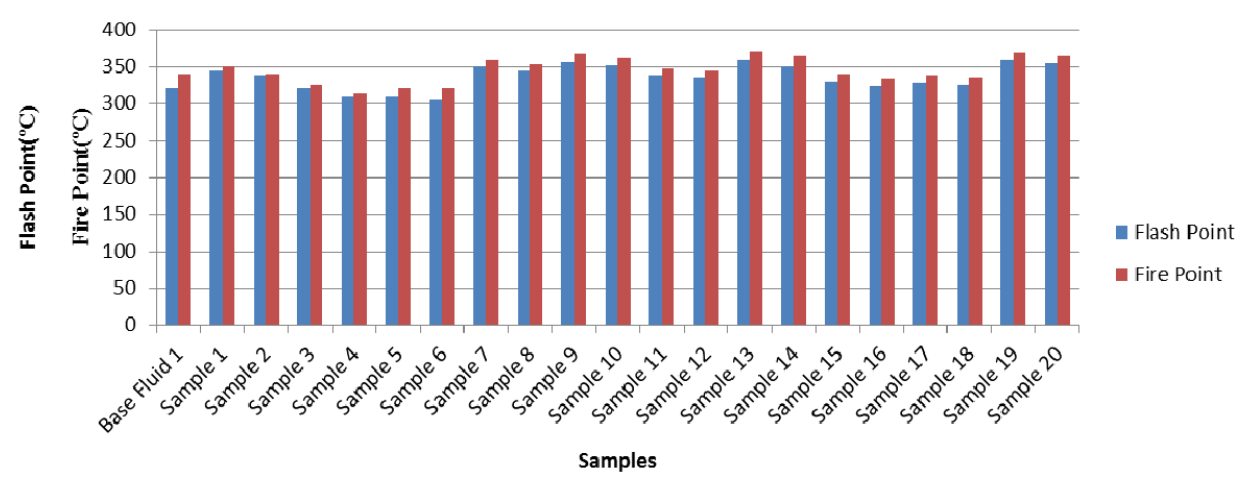

Fig. 7. Flash and Fire point of Base Fluid 1

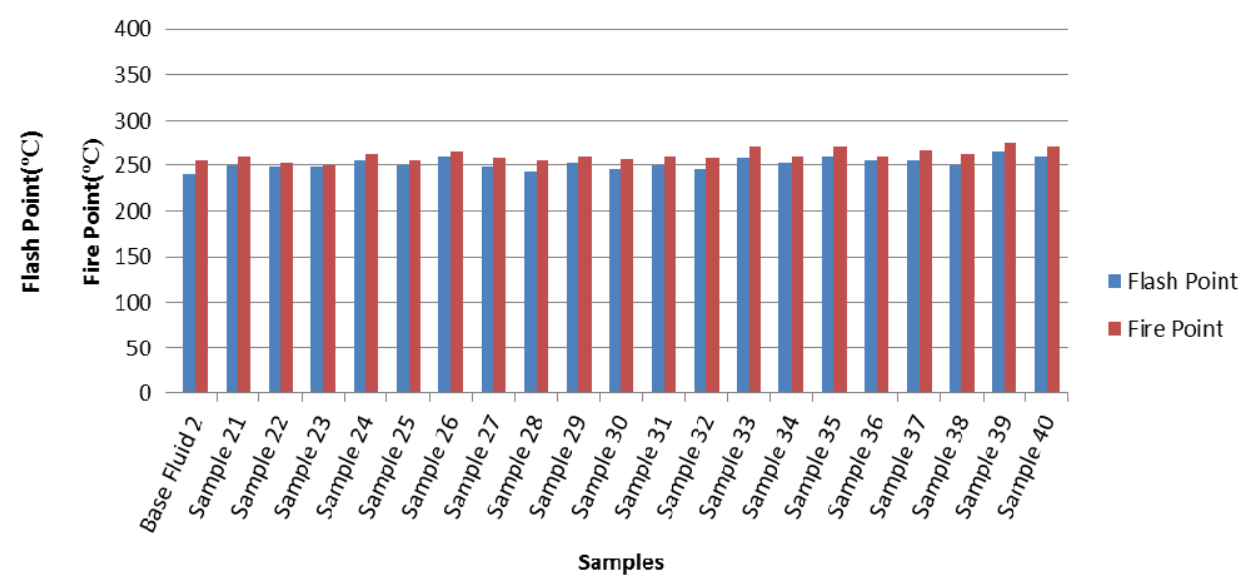

Fig. 8. Flash and Fire point of Base Fluid 2

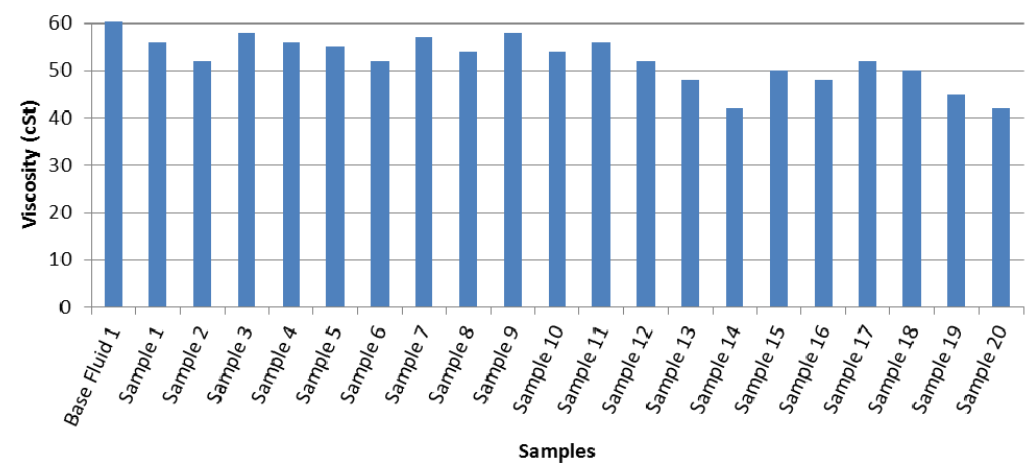

Fig. 9. Viscosity of Base Fluid 1 with additives

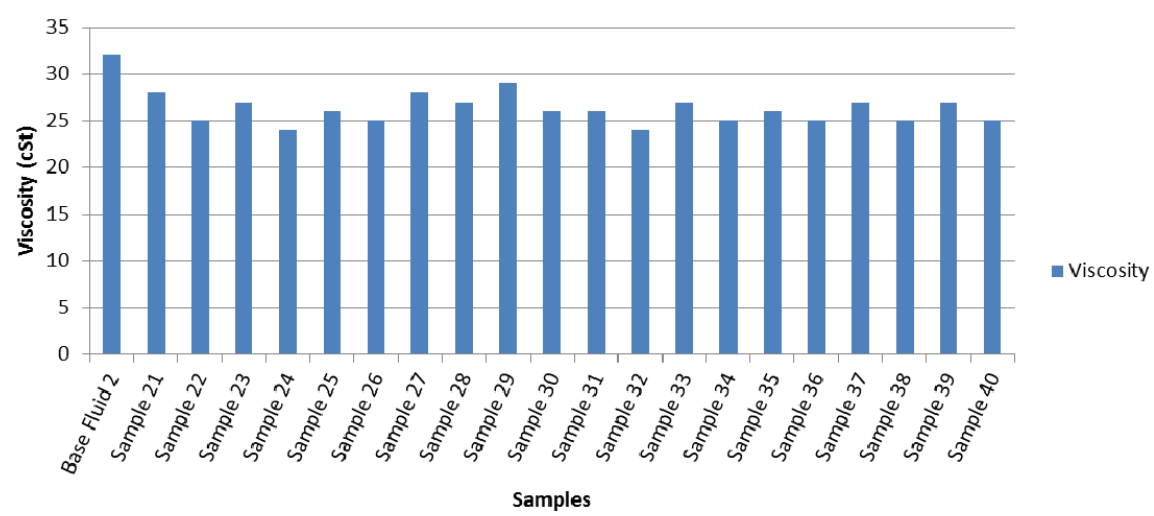

Fig. 10. Viscosity of Base Fluid 2 with additives 
Table 8. Flash point and Fire point of the base fluids with antioxidants

\begin{tabular}{|c|c|c|c|c|c|}
\hline \multirow[b]{2}{*}{ Antioxidants } & \multirow[b]{2}{*}{$\begin{array}{l}\text { Weight in } \\
\text { gms }\end{array}$} & \multicolumn{2}{|c|}{ Base fluid 1} & \multicolumn{2}{|c|}{ Base fluid 2} \\
\hline & & $\begin{array}{l}\text { Flash } \\
\text { Point } \\
\left({ }^{\circ} \mathrm{C}\right)\end{array}$ & $\begin{array}{c}\text { Fire } \\
\text { Point } \\
\left({ }^{\circ} \mathrm{C}\right)\end{array}$ & $\begin{array}{l}\text { Flash } \\
\text { Point } \\
\left({ }^{\circ} \mathrm{C}\right)\end{array}$ & $\begin{array}{l}\text { Fire } \\
\text { Point } \\
\left({ }^{\circ} \mathrm{C}\right)\end{array}$ \\
\hline \multirow{2}{*}{$\begin{array}{c}\alpha- \\
\text { TOCOPHEROL }\end{array}$} & 5 & 345 & 350 & 235 & 245 \\
\hline & 2.5 & 338 & 340 & 232 & 242 \\
\hline \multirow{2}{*}{ Ascorbic acid } & 5 & 320 & 325 & 240 & 250 \\
\hline & 2.5 & 310 & 315 & 234 & 246 \\
\hline \multirow{2}{*}{ Citric acid } & 5 & 310 & 320 & 236 & 246 \\
\hline & 2.5 & 305 & 320 & 230 & 242 \\
\hline \multirow{2}{*}{ BHA } & 5 & 350 & 360 & 248 & 258 \\
\hline & 2.5 & 344 & 354 & 243 & 255 \\
\hline \multirow{2}{*}{ BHT } & 5 & 357 & 367 & 252 & 260 \\
\hline & 2.5 & 352 & 362 & 246 & 257 \\
\hline \multirow{2}{*}{ PG } & 5 & 338 & 348 & 250 & 260 \\
\hline & 2.5 & 335 & 345 & 246 & 258 \\
\hline \multirow{2}{*}{$\mathrm{BHA}+\mathrm{BHT}$} & $2.5+2.5$ & 360 & 370 & 258 & 270 \\
\hline & $1.25+1.25$ & 350 & 365 & 252 & 260 \\
\hline \multirow{2}{*}{$\mathrm{BHT}+\mathrm{CA}$} & $2.5+2.5$ & 330 & 340 & 260 & 270 \\
\hline & $1.25+1.25$ & 324 & 334 & 255 & 260 \\
\hline \multirow{2}{*}{$\mathrm{BHT}+\mathrm{AA}$} & $2.5+1.5$ & 328 & 338 & 256 & 267 \\
\hline & $1.25+1.25$ & 325 & 335 & 250 & 262 \\
\hline \multirow{2}{*}{$\mathrm{BHT}+\alpha-\mathrm{T}$} & $2.5+2.5$ & 359 & 369 & 265 & 275 \\
\hline & $1.25+1.25$ & 355 & 365 & 260 & 270 \\
\hline
\end{tabular}

\subsection{Viscosity}

The transformer insulating fluid serves as heat conduction medium irrespective of its dielectric property. The viscosity of fluid is very important in the convection process of heat transfer and temperature is a factor which decides the viscosity. The samples were tested at temperature of $40^{\circ} \mathrm{C}$. Even at higher temperature the viscosity value will get reduced but this leads to formation of free radicals which results in sludge formation. The test results of samples are shown in Table 7 and are represented in Figs. 9 and 10. The viscosity is inversely proportional to flow rate. As the viscosity decreases, the flow rate increases thereby enhancing the heat absorption. The samples S14, S20 of base fluid 1 and S24, S32 of base fluid 2 with the combination of antioxidants have shown decrement of viscosity value giving a better scope for high flow rate thereby making them worthy of heat absorption property.

\section{Conclusion}

The test results show the effective performance of natural esters with the antioxidants. The breakdown voltage and Flash/Fire point of base fluid 1 and 2 have been enhanced with the additives of BHA, BHT, and $\alpha-T$. The viscosity of test fluids has been decremented by the additives BHT, $\alpha-\mathrm{T}$, and PG. Thus the vegetable oils selected for this study can be used as alternative insulating fluids in transformers.
The transformed natural esters are better alternatives for transformer mineral oil as they offer higher oxidation stability and less formation of gas during reaction. The natural esters are eco-friendly and the aged oil can be easily disposed. The costs of transformed natural esters are more compared with transformer mineral oil. Nevertheless, they are preferable because of their long life and less environmental pollution.

\section{References}

[1] Vishal, Saurabh, Vikas and Prashant, "Transformer's History and its Insulating Oil", 5th National Conference INDIACom-2011, Computing For Nation Development, March 10 - 11, 2011.

[2] M. Porta, E. Zumeta, "Implementing the Stockholm Treaty on Persistent Organic Pollutants", Occupational and Environmental Medicine 10 (59): 651-2.

[3] G. Mercier, "WEMCOL capacitor fluid development," Electrical/Electronics Insulation Conference, Chicago, 1977.

[4] H. R. Sheppard, "Century of Progress in Electrical Insulation 1886-1986" IEEE Electrical Insulation Magazine, vol. 2, Issue: 5, pp. 20-30, Sept. 1986.

[5] Lee, and K. Neville, "Handbook of Epoxy Resins", McGraw Hill Book Company, 1967.

[6] T.V. Oommen, "Vegetable oils for liquid-filled transformers" IEEE Electrical Insulation Magazine, vol.18, Issue 1, pp. 6-11. Jan. - Feb. 2002.

[7] T. S. Ramu, "On the high frequency dielectric behavior of castor oil," IEEE Trans. Elec. Insul., vol. EI-14, no. 3, pp. 136-141, 1979.

[8] K.P. Mammootty and T.S. Ramu, "Properties of castor oil impregnated all- polypropylene and polypropylenepaper capacitors," IEEE Trans. Elec. Insul., vol. EI18, no. 5, pp. 541-550, 1983.

[9] D.C. Abeysundara, C. Weerakoon, J.R. Lucas, K.A.I. Gunatunga and K.C. Obadage, "Coconut Oil as an Alternative to Transformer Oil", Engineering Research Unit Sympos. Morutuwa, Srilanka, pp. 12-22, 2001.

[10] A. U. Biermann and J. O. Metzger, "Report: "Application of Vegetable Oil Based- Fluids as Transformer Oils", Faculty of Mathematics and Natural Sciences, Carl Von Ossietzky University, Oldenburg, Germany, 2007.

[11] ABB INC (2002), Vegetable Oil - Based Insulating Dielectric Fluid. The Environmental Technology Verification Program Joint Verification Statement.

[12] S. Ranawana, C.M.B. Ekanayakal, N.A.S.A. Kurera, M.A.R.M. Fernando and K.A.R. Perera, "Analysis of Insulation Characteristics of Coconut Oil as an Alternative to the Liquid Insulation of Power Transformers", IEEE Region 10th Colloquium and the Third Int'l.Conf. on Industrial and Information Systems, Kharagpur, India, pp. 1- 5, 2008. 
[13] O.A. Emmanuel and O.J. Mudiakeoghene, "The use of antioxidants in vegetable oils-A review", African $J$. Biotechnology, Vol. 7, pp. 4836- 4842, 2008.

[14] A. Raymon, P. Samuel Pakianathan, M. P. E. Rajamani and R. Karthik, "Enhancing the Critical Characteristics of Natural Esters with Antioxidants for Power Transformer Applications", IEEE Transactions on Dielectrics and Electrical Insulation, Vol. 20, No. 3, pp. 899-912, June 2013

[15] G. Scott, "Atmospheric Oxidation and Antioxidants", Elsevier Publishing Company, Amsterdam, London, New York, 1965.

[16] P. K. J. P. D. Wanasundara and F. Shahidi, "Report: "Antioxidants:Science,Technologyand Applications", Bailey's Industrial Oil and Fat Products, Vol. 6, No. 6, pp. 431-489, 2005.

[17] Raymon. A., and Karthik R., "Reclaiming and Enhancing the Aged and Fresh Transformer Oil with Activated Bentonite and Antioxidants" IEEE Transactions on Dielectrics and Electrical insulation, Vol22, No.1. pp. 548-555, Feb-2015.

[18] Bennion M, "Introductory Foods", 10th Edition. Prentice-Hall Inc., Upper Saddle River, New Jersey, USA, 1995.

[19] R. Badent, K. Kist, B. Riiggemeier, W. Zierhut, A.J. Schwab, "Dielectric Characteristics of Rape-Seed Oil", Annual Report Conference on Electrical Insulation and Dielectric Phenomena (Cat. No. 98CH36257, pp. 456-459, 1998.

[20] R. Badent, M. Hemmer, A. J. Schwab, "Inhibited rape-seed oil as substitute for mineral oils", Annual Report Conference on Electrical Insulation and Dielectric Phenomena, pp. 268-271, Jan.- Feb. 2002.

[21] M. S. Khayoon, M. A. Olutoye, B. H. Hameed, "Utilization of crude karanj (Pongamia pinnata) oil as a potential feedstock for the synthesis of fatty acid methyl esters", Bioresource Technology 111, 175-179, 2012.

[22] Rui Wang a,b, Milford A. Hanna c, Wan-Wei Zhou a, Pinaki S. Bhadury a, Qi Chen a, Bao-An Song a,Song Yang "Production and selected fuel properties of biodiesel from promising non-edible oils: Euphorbia lathyris L., Sapium sebiferum L. and Jatropha curcas L", Bioresource Technology 102, 1194-1199, 2011.

[23] P. Boss and T.V. Oommen, "New Insulating Fluids for Transformers based on Biodegradable High Oleic Vegetable Oil and Ester Fluid", IEE Colloquium on Insulating Liquids, London, UK, Vol. 7, pp. 1-10, 1999.

[24] FD Gunstone. Fatty Acid and Lipid Chemistry, Blackie Academic and Professional, London, 252 pp, 1996.

[25] IEC 60156 Third edition, "Insulating liquids-Determination of the breakdown voltage at power frequency-Test method", 2003-11

[26] R. Karthik, T.S.R. Raja and S. Madavan, "Enhance- ment of Critical Characteristics of Transformer Oil Using Nano Materials", Arabian J.Sci. Eng., Springer Publications, Vol. 3, No. 20, pp. 369-374, 2012.

[27] R. Karthik, T.S.R. Raja, S.S. Shanmugam and T. Sudhakar, "Performance Evaluation of Ester oil and Mixed Insulating Fluids", J.Inst. Eng., India, Series B, Vol. 93, No. 3, pp. 173-178, 2012.

[28] IEEE Std 637TM-1985(R2007) - EEE Guide for the Reclamation of Insulating Oil and Criteria for Its Use.

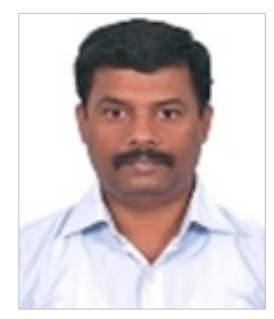

R. Thanigaiselvan $\mathrm{He}$ received the B.E. degree in Electrical and Electronics Engineering from Manonmaniam Sundaranar University, Tirunelveli and M.E. degree in Applied Electronics from Anna University, Chennai, Tamil Nadu, India. Currently he works at Anna University, Bharathidasan Institute of Technology, Tiruchirappalli, Tamil Nadu, India. And also pursuing Ph.D. degree at Anna University. His area of research interest includes High voltage Engineering, Insulators.

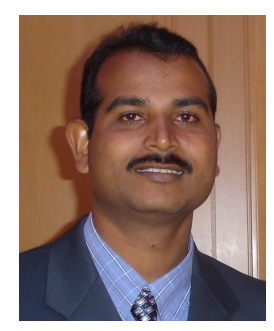

T. Sree Renga Raja He obtained B.E degree in Electrical and Electronics Engineering from Manonmaniam Sundaranar University, Tirunelveli, M.E degree in Power Systems from Annamalai University, Chidambaram, India and $\mathrm{Ph} . \mathrm{D}$ degree from Anna University, Chennai, India. He has published many papers in the field of Power System. His research interest includes Power systems, High Voltage Engineering, Energy Management and Insulation Engineering.

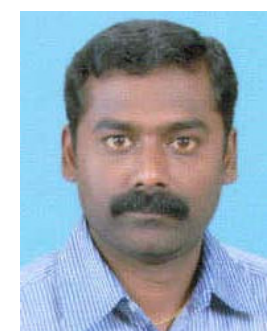

R. Karthik $\mathrm{He}$ is an Assistant Professor (senior grade) in the Department of Electrical Engineering, Liquid Dielectrics laboratory, National Engineering College, Kovilpatti, Tamilnadu, India. He obtained his B.E (Electrical) degree from the University of Madras, M.Tech (High Voltage Engineering) from SASTRA University, Thanjore and Ph.D. degree from Anna University, Chennai, India. He has published many papers in Conferences and Journals. 